\title{
The role of acetylsalicylic acid and circulating microRNAs in primary prevention of cardiovascular events in patients with Diabetes Mellitus Type 2 - A Review
}

\author{
Aleksandra Chabior ${ }^{1,2, B-D}$, Justyna Pordzik ${ }^{2,1, C, E-F}$, Dagmara Mirowska-Guzel,2,F, Marek Postuła ${ }^{1,2, E-F}$ \\ ${ }^{1}$ Medical University, Warsaw, Poland \\ ${ }^{2}$ Department of Experimental and Clinical Pharmacology / Center for Preclinical Research and Technology (CePT), \\ Medical University, Warsaw, Poland \\ A - Research concept and design, B - Collection and/or assembly of data, C - Data analysis and interpretation, \\ $D$ - Writing the article, E - Critical revision of the article, F - Final approval of article
}

Chabior A, Pordzik J, Mirowska-Guzel D, Postuła M. The role of acetylsalicylic acid and circulating microRNAs in primary prevention of cardiovascular events in patients with Diabetes Mellitus Type 2 - A Review. Ann Agric Environ Med. 2019 ; $26(4)$ : 515-522. doi: $10.26444 /$ aaem/100391

\section{Abstract}

Introduction. Type 2 diabetes mellitus (T2DM) is a common metabolic disorder, which carries a risk for atherosclerosis and cardiovascular impairment. The purpose of this review is to demonstrate the role of acetylsalicylic acid (ASA) in primary cardiovascular prevention in T2DM patients, as well as present an outline of microRNAs (miRNA) relevant to ASA therapy and should be evaluated as targets to improve treatment.

Brief description of state of knowledge. Although the etiology of hypercoagulable state in T2DM is considered multifactorial, attention mainly focuses on platelet disturbances. Platelets in T2DM not only demonstrate intensified adhesion, activation, aggregation, and thrombin generation, but are likely to deliver miRNAs at specific sites of action in the cardiovascular system, hence contributing to the pathogenesis of cardiovascular events.

Objective. Since cardiovascular disease (CVD) is currently the leading cause of mortality among T2DM patients, appropriate risk stratification and management is necessary to reduce morbidity and mortality in this group. A large number of T2DM patients show inadequate response to antiplatelet therapy, which currently revolves around ASA, despite compliance with treatment regimens proposed by the guidelines.

Conclusions. The review shows that the use of ASA for primary prevention is beneficial in patients at high cardiovascular risk. However, it is important to select patients in whom ASA therapy will bring the most beneficial outcome with minimal risk for adverse effects. This can be potentially achieved with the use of unique biomarkers. The biologically diverse characteristics of miRNA make them a promising novel biomarker and potential tool for better risk stratification, as well as antiplatelet therapy optimization.

\section{Key words}

diabetes mellitus, primary prevention, platelets, acetylsalicylic acid, microRNA

\begin{abstract}
Abbreviation
ASCEND - Study of Cardiovascular Events iN Diabetes, ACBS (Asymptomatic Cervical Bruit Study), ASA - Acetylsalicylic acid, ADP - Adenosine diphosphate, ADA - American Diabetes Association, AHA - American Heart Association, ACC American College of Cardiology, APLASA - Antiphospholipid Antibody Acetyl-salicylic Acid study, ACCEPT-D - Aspirin and Simvastatin Combination for Cardiovascular Events Prevention Trial in Diabetes, AAA - Aspirin for Asymptomatic Atherosclerosis Trial, BDT - British Doctors Trial, CV - Cardiovascular, CVD - Cardiovascular disease, CLIPS - Critical Leg Ischaemia Prevention Study, CHD - Coronary heart disease, COX-1 - Cyclooxygenase-1, ETDRS - Early treatment Diabetic retinopathy Study, ECLAP - European Collaboration on Low-Dose Aspirin in Polycythemia Vera study, ESC - European Society of Cardiology, GI - Gastrointestinal, HOT - Hypertension Optimal Treatment, IMPACT - IMProving Adherence using Combination Therapy, JPAD - Japanese Primary Prevention of Atherosclerosis With Aspirin for Diabetes, KanyaniGAP - Kanyini Guidelines Adherence with Polypill, MACE - Major adverse cardiovascular event, mRNA - Messenger RNA, miRNA - MicroRNA, MVs - Microvesicles, MI - Myocardial infarction, NSAIDs - Nonsteroidal anti-inflammatory drugs, PSAD - Peripheral artery disease, PHS - Physicians' Health Study, PAF - Platelet-activating factor, PMVs - platelet microvesicles, POPADAD - Prevention of progression of arterial disease and diabetes, PPP - Primary prevention Project, PCR - real-time polymerase chain reactions, RR - Relative risk, TPT - Thrombosis Prevention Trial, TIA - Transient ischemic attack, T2DM - Type 2 diabetes mellitus, UMPIRE - Use of a Multidrug Pill In Reducing Cardiovascular Events, von WillevWF) - brand factor, WHS - Women's Health Study.
\end{abstract}

Address for correspondence: Marek Postuła MD, PhD, Warsaw Medical University, Zwirki i Wigury 61, 02-091 Warsaw, Poland

e-mail:mpostula@wum.edu.pl

Received: 28.07.2018; accepted: 28.11.2018; first published: 31.01 .2019

\section{INTRODUCTION}

Type 2 diabetes mellitus (T2DM), a chronic metabolic disease characterized by hyperglycaemia, is a common disorder 
which carries a risk for atherosclerosis and cardiovascular (CV) impairment $[1,2]$. The burden of this rapidly expanding and lifelong condition is extremely high due to the increasing incidence and prevalence of other public health threats, including obesity, urbanization, and ageing of the world population. The significance of T2DM as a CV risk factor is hence expected to increase even further in the coming years [3].

Type 2 diabetes mellitus became known as a wellestablished contributor to acute ischemic events after a landmark study conducted by Haffner et al., and nowadays is considered a leading risk factor for CV events $[4,5]$. Since cardiovascular disease (CVD) is currently the leading cause of mortality among T2DM patients, appropriate risk stratification and management is necessary to reduce morbidity and mortality in this group [1]. The intertwined communication between the vulnerable atheromatous plaque and activated vascular cells (i.e. platelets, endothelial cells, leukocytes) is a crucial contributor to the increased atherothrombotic burden in T2DM patients; however, the cellular and molecular mechanisms underlying the amplified thrombotic propensity in T2DM remain to be fully elucidated [6]. Despite considerable progress in the development of pharmacological treatment modalities, there is no consensus of optimal, tailored and individual-focused antiplatelet therapy for primary prevention in T2DM. A significant percentage of T2DM patients show inadequate response to standard antiplatelet medications, which currently revolves around acetylsalicylic acid (ASA), despite compliance with treatment regimens proposed by the guidelines $[7,8,9,10,11]$. Thus, new antiplatelet treatment modalities are sought for.

Since the current laboratory tests and biomarkers reflect the increased risk of thrombosis only to a certain extent, it is necessary to lay foundations to discover novel diagnostic tools that could be applied clinically in T2DM patients before major CV complications occur. The recent global interest and results emerging on miRNAs studies indicate that these small molecules might have a causative role in T2DM and related $\mathrm{CV}$ complications.

\section{OBJECTIVE}

The purpose of this review is to demonstrate the role of ASA in primary CV prevention in T2DM patients, as well as present an outline of microRNA (miRNA) relevant to T2DM CV complications and should be evaluated as targets to improve treatment.

The electronic medical database Pubmed was searched on 20 December 2017 for studies evaluating the role of ASA and circulating miRNAs in the primary prevention of CVD in T2DM. Both meta-analyses and review articles were scrutinized for possible inclusion and limited to human studies only. Search terms comprised of the following key words: ASA, microRNA, primary prevention, cardiovascular diseases, diabetes.

Mechanisms of hypercoagulable state in T2DM. Type 2 diabetes mellitus has been previously described as a prothrombotic state, induced by pathological changes in platelets, endothelium and the coagulation system. Although the etiology of hypercoagulable state is considered multifactorial, attention is mainly focused on hyperglycaemia, which plays a pivotal role in the platelet disturbances observed in T2DM patients [3, 12]. Furthermore, coagulation derangements are linked to insulin resistance, oxidative stress, and the metabolic status of diabetic (DM) patients, often complicated by obesity, dyslipidemia and abnormal inflammatory responses $[12,13,14]$.

"Diabetic platelets" are known to play a particularly significant role in the prothrombotic state as they show a wide scope of typical features. Platelets contain multiple receptors which trigger the physiological response through certain agonists, including adenosine diphosphate (ADP), epinephrine, collagen, thrombin, serotonin, and plateletactivating factor (PAF). Once activated, they exhibit an enhanced adhesiveness and aggregation. The intensified adhesion, activation, aggregation, and platelet-derived thrombin generation are all abnormalities unique to T2DM platelets [15]. Moreover, disturbances in the pro-inflammatory state and endothelial dysfunction observed in T2DM further contribute to the phenomenon of the hypercoagulable state $[16,17]$. Interestingly, platelets also have the ability to translate inherited messenger RNA (mRNA) into protein, despite lacking their own nucleus and DNA [18]. MiRNAs are as small, endogenous, noncoding RNAs which regulate a considerable proportion of protein coding genes, primarily through the interaction with mRNAs $[19,20]$. This effect is exerted by binding the corresponding parts of mRNA transcripts to suppress their translation and control degradation [21]. Upon activation, microvesicles (MVs) containing growth factors and numerous effector proteins with the capacity to exert extracellular effects are released from platelets [22]. In these MVs platelets are likely to deliver miRNAs at specific sites of action in the cardiovascular system, hence contributing to the pathogenesis of cardiovascular events [23].

Type 2 diabetes mellitus strongly correlates with the occurrence of both micro- and macrovascular complications over the course of disease [24]. As a consequence of accelerated progression of atherosclerosis and atherothrombosis, diabetics are more susceptible to developing CV events, which currently represent the major contributor to morbidity and mortality in this population [24, 25].

A landmark study by Haffner et al. showed that mortality in DM patients without a history of myocardial infarction (MI) is comparable to that observed in non-DM patients with a history of MI [4]. In line with the presented results, T2DM has been categorized as a coronary risk equivalent [26]. Higher rates of recurrent atherothrombotic events in T2DM patients, compared to non-T2DM patients, have also been reported in other studies [27].

The above-mentioned studies support the need for T2DM subjects to receive personalized antiplatelet therapy strategy to reduce atherothrombotic events associated with hyperactive platelets [28].

Acetylsalicylic acid (ASA) - mechanism of action. Acetylsalicylic acid is the cornerstone of primary cardiovascular prevention in T2DM and is widely known as the oldest, most affordable, and easily available drug used for this purpose worldwide $[29,30]$. Its mechanism of action relies on irreversible inhibition of cyclooxygenase-1 (COX-1) activity, which in turn blocks the conversion of arachidonic acid to prostaglandin and the production of thromboxane A2, which mediates platelet aggregation. Altogether, these steps halt platelet aggregation $[29,31]$. It is worth mentioning, 
that other drugs which inhibit COX-1, such as nonsteroidal anti-inflammatory drugs (NSAIDs), do so reversibly [32]. Contrary to these, ASA exerts this effect irreversibly because the platelets lack a nucleus, and therefore cannot sustain resynthetization of COX-1 [33]. Meta-analyses evaluating the use of ASA in primary
prevention of cardiovascular diseases in diabetes. Between 1988 - 2018, multiple randomized clinical trials were performed to assess the usefulness of ASA in primary prevention of CVD [Tab. 1]. To-date, several meta-analyses have been conducted to investigate the impact of ASA therapy on CV events in primary prevention in T2DM.

Zhang et al. performed a meta-analysis which included seven prospective randomized trials: Physicians' Health Study (PHS), Early Treatment Diabetic Retinopathy Study (ETDRS), Hypertension Optimal Treatment (HOT), Primary prevention Project (PPP), Women's Health Study (WHS), Prevention Of Progression of Arterial Disease And Diabetes (POPADAD) and Japanese Primary Prevention of Atherosclerosis With Aspirin for Diabetes (JPAD). The aim of this analysis was to assess the effect of ASA in primary prevention of DM patients with follow-up atleast 12 months later. The total number of patients was 11,618, and from the whole cohort 5,826 were assigned to ASA administration and 5,792 to the control group with placebo. The dosage of ASA varied in each trial between $50 \mathrm{mg} /$ day and $650 \mathrm{mg} /$ day. The risk of major $\mathrm{CV}$ events was lower in the group with ASA (11.1\%), in comparison to the placebo group (12.1\%). The pooled relative risk (RR) indicated an $8 \%$ decrease in major adverse cardiovascular events (MACE) $(0.88,95 \%$ CI $0.67-1.15 ; \mathrm{p}=0.11)$.

Treatment with ASA did not significantly reduce the rate of $\mathrm{CV}$ deaths, $\mathrm{MI}$, stroke and all-cause mortality. It is worth noting that these meta-analysis meta-regression and subgroup analysis were performed in order to show that ASA administration can decrease the risk of stroke in DM women and MI in DM men. They demonstrated that there are non-significant benefits of treatment with ASA in primary prevention of CV events, and showed gender-specific outcome of ASA [34]. Bartolucci et al. conducted a metaanalysis of nine trials (published up to 2011, i.e. BDT, PHS, TPT, HOT, PPP, WHS, AAA, POPADAD, and JPAD trials). The aim of this meta-analysis was to investigate recent trials (AAT, JPAD, POPADAD) and add data to extend the sample from previous Bartolucci meta-analysis [35-36]. This helped to assess more accurately the differences between cohorts. In these trials, 50,868 patients were treated with ASA and 49,170 received placebo or control. Healthy patients were included in seven investigated trials, but only POPADAD and JPAD trials recruited patients with DM without symptoms of CVD. End points for these nine trials were the total occurrence of coronary heart disease (CHD), non-fatal MI, total CV events, stroke, CV mortality and all-cause mortality. The results of the meta-analysis presented a significant decrease in nonfatal MI (odds ratio, OR 0,813; $\mathrm{p}=0.042$ ) and total CV events (OR 0.865; $\mathrm{p}=0.0001$,) in patients undergoing ASA treatment. Most studies present OR $<1$ with total benefit of ASA over placebo. Nevertheless, ASA was not beneficial for stroke prevention, CHD, CV mortality and all-cause mortality. The study showed heterogeneity among trials mainly caused by patient selection and randomization, disease severity and treatment options, which did not affect the overall difference between ASA and placebo [35]. Butalia et al. performed a meta-analysis to reevaluate recommendation of ASA for prevention of MACE (non-fatal MI, non-fatal stroke, and cardiovascular death) in only DM subjects. They included seven randomized clinical trials (PHS, ETDRS, HOT, PPP, WHS, POPADAD, JPAD) with a total number of $11,618 \mathrm{DM}$ patients. Participants were randomized to ASA or placebo groups and the dose of ASA varied between $75 \mathrm{mg}-650 \mathrm{mg}$ every day or every other day. After a follow-up period of 3.6 - 10.1 years, the risk of primary and secondary endpoint, named as MACE (95\% confidence intervals; CI 0.82-1,00), non-fatal and fatal MI (relative risk, RR 0.85; 95\% CI, 0.661.10), ischemic stroke (RR 0.84; 95\% CI 0.64-1.11, CV death (RR 0.95; 95\% CI 0.71-1.27), and all-cause mortality (RR 0.95; 95\% CI 0.85-1.06) was not significantly different between the two groups. Haemorrhagic and gastrointestinal (GI) events occurred more often in the ASA group, but without any statistical significance. In conclusion, DM patients were at higher risk of CV events, thus the administration of ASA in primary prevention should be individually considered [37].

Furthermore, Stavrakis et al. conducted a meta-analysis on a population which consisted of DM subjects with no previous history of CVD. They investigated the safety and efficacy of low-dose ASA and attempted to find evidence of its efficacy in primary prevention. They evaluated seven clinical randomized trials, two of which investigated only DM patients, the other five trials had subgroups of patients with DM. The results showed a non-significant reduction in MACE (RR 0.89; 95\% CI 0.70-1.13) in the group with ASA. Likewise, there was a non-statistically significant reduction in the risk of stroke, MI, CV and all-cause mortality. The rate of major bleeding was elevated non-significantly in the ASA group (RR 3.02; 95\% CI 0.48-18.86). The effects of primary prevention with low-dose ASA remain undefined properly and should be further investigated [38].

Sutcliffe et al., on the other hand, performed a systemic review of nine randomized clinical trials (POPADAD, BDT, JPAD, AAA, HOT, TPT, PPP, PHS and WHS). Twenty-seven papers were included, twenty two systematic reviews and five randomized clinical trials, which studied primary prevention of CVD and CVD in individuals with T2DM. ASA was correlated with reduction of RR $-6 \%$ for all-cause mortality (RR 0.94; 95\% CI 0.88-1.00), 10\% for MACE (RR 0.90; 95\% CI $0.85-0.96$ ) and $15 \%$ for CHD (RR 0.85 ; 95\% CI $0.69-$ 1.06). ASA therapy was associated with increased risk of GI bleeding (RR 1.37, 95\% CI 1.15-1.62). Meta-analyses of DM patients with no history of CV events were underpowered and accurate findings could not be obtained.

The presented review demonstrates that the use of ASA for primary prevention is modest, not proven to be beneficial and is related with higher risk of GI bleeding. Nowadays, many other possibilities of prevention exist, e.g. lipid lowering and controlling of blood pressure and are more likely to prevent CV events [39]. Moreover, another meta-analysis, based on thirteen trials (PHS, BDT, TPT, HOT, PPP, WHS, POPADAD, JPAD, AAA, ETDRS and APLASA, ECLAP, CLIPS, and ACBS. The aim of this meta-analysis was to reevaluate current guidelines, benefits of ASA and show the effects of ASA depending on gender and diabetes status in primary prevention. The results suggest that the use of ASA is beneficial and significantly reduces the risk of CV events in both genders, but is more likely to reduce the rate of $M I$ among men (RR 0.71; 95\% CI, 0.59-0.85) and ischemic stroke 
among women (RR 0.77; 95\% CI 0.63-0.93). ASA did not decrease CVD rate in the group with DM, but was linked to reduction in MI (RR 0.65; 95\% CI 0.51-0.82) among men with DM. In addition, the analysis showed that low doses of ASA (75 mg/day) reduced the risk of CVD similarly to high-doses $(650 \mathrm{mg} /$ day), and that ASA treatment should be considered individually [40].

The SPACE Collaboration performed meta-analysis of UMPIRE, Kanyani-GAP and IMPACT trials to evaluate the impact of fixed dose combination pill on subjects at high risk of CVD or subjects with CVD. The investigators based on individual patient data from three clinical trials. A total of 3,140 individuals from various countries were randomized to treatment with the Red Heart Pill (ASA $75 \mathrm{mg}$, simvastatin $40 \mathrm{mg}$, lisinopril $10 \mathrm{mg}$, atenolol $40 \mathrm{mg}$ or hydrochlorothiazide $12.5 \mathrm{mg}$ ), or to standard regimen (e.g. antiplatelet, blood pressure lowering and cholesterol lowering as separate drugs). During the follow-up, patients treated with polypill had higher compliance in comparison to patients on usual therapy ( $80 \%$ vs. 50\%, RR 1.58; 95\% CI, 1.32 -1,90; p < $0.001)$, decreased systolic blood pressure (SBP) $(-2.5 \mathrm{mmHg}$; $95 \% \mathrm{CI},-4.5$ to $-0,4 ; \mathrm{p}=0.02)$ and LDL-cholesterol level $(-0.1$ $\mathrm{mmol} / \mathrm{L} ; 95 \% \mathrm{CI},-0.2-0.0 ; \mathrm{p}=0.04)$. The outstanding feature of the SPACE Collaboration meta-analysis showed that polypill treatment is beneficial and significantly improves compliance among high risk patients [41].

Kokoska's et al. meta-analysis consisted of six studies from various countries, four of which were primary studies (ETDRS, PPP, POPADAD, JPAD), and two were randomized clinical trials (PHS, WHS). Previous meta-analyses did not assess atherosclerotic events, such as angina, transient ischemic attack (TIA), peripheral artery disease (PAD) and revascularization. Therefore, this meta-analysis included additional atherosclerotic endpoints and evaluated ASA therapy in primary prevention of DM subjects. In total, 10,117 subjects with diabetes were evaluated, of whom 5,064 received ASA and 5,053 received placebo. ASA doses ranged between $100 \mathrm{mg}$ every other day and $650 \mathrm{mg}$ daily. Rates of all-cause mortality between individuals on ASA therapy and placebo groups were almost equal (OR 0.93; 95\% CI 0.81-1.06). CV mortality was also similar. Kokoska et al. observed 298 deaths from CV causes in a group receiving ASA in comparison to 328 deaths in placebo group (OR 0.4; 95\% CI 0.1-1.6). Occurrence of fatal or non-fatal MI, stroke, TIA, PAD and revascularization were also similar. In the 5,64 cohort treated with ASA, atal or non-fatal MI appeared in 395 subjects versus 439 subjects in the placebo group (OR $0.87 ; 95 \%$ CI 0.63-1.20), which is a non-significant difference. In summary, it is unclear whether ASA is beneficial in the primary prevention of $\mathrm{CV}$ events [42].

The most recent, ongoing trials are ASCEND and ACCEPT-D. Both trials recruit patients with diagnosis of type 1 or 2 diabetes mellitus without occlusive vascular disease. The aim of these trial was to determine the efficacy and safety of ASA in the reduction of MACE in the DM population $[43,44]$.

Current ASA therapy recommendations in primary prevention of cardiovascular diseases in T2DM. Even though multiple guidelines have been published with respect to the use of ASA in primary cardiovascular prevention in T2DM worldwide, the recommendations are often conflicting.
According to the latest (2016) ADA guidelines, ASA use for primary cardiovascular prevention in T2DM is recommended for subjects with a 10 -year risk of CVD $>10 \%$, and on an individual basis in subjects with an intermediate 10 -year risk of $5-10 \%[7,8]$. These recommendations are in line with a Joint Scientific Statement by ADA, AHA and ACC (2010) [9].

In the 2016 ESC guidelines on CVD prevention, the use of ASA is not an endorsed primary prevention strategy in T2DM patients unless they have overt CVD [10]. However, the ESC Working Group on Thrombosis recommends ASA in T2DM subjects at high risk of major cardiovascular events, without clear evidence of increased risk of bleeding [11].

Markers of hypercoagulability in diabetes - potential role of circulating miRNAs. The available evidence suggests that ASA therapy for primary prevention is beneficial in patients at high cardiovascular risk, including T2DM patients. However, due to its relatively serious side effects it is important to select patients in whom ASA therapy will bring the possibly best outcome with minimal risk for adverse effects. This can be potentially achieved with the use of unique biomarkers $[45,46]$.

Increased risk of thrombosis in T2DM patients is evidently mirrored by altered laboratory test results. Until now, multiple markers of platelet activation and endothelial dysfunction have been determined and their diagnostic, as well as prognostic value, is considered high enough for potential application in a regular clinical setting [47-51].

Kubisz et al. composed a list of the most significant markers of DM thrombocytopathy, which included betathromboglobulin, glycoprotein $\mathrm{V}$, mean platelet volume, platelet factor 4 and thrombospondin 1, among others [2]. Endothelial dysfunction markers, regarded as the most important, were identified as plasminogen activator inhibitor 1 antigen, thrombin-activatable fibrinolysis inhibitor antigen, total tissue factor pathway inhibitor antigen, free tissue factor pathway inhibitor antigen, thrombomodulin antigen, ttissue plasminogen activator antigen and von Willebrand factor (vWF) antigen. Moreover, markers of activated haemostasis, such as prothrombin activation fragment $1+2$ and thrombinanti-thrombin complexes, fibrinogen plasma levels, factors VII, VIII, XI and XII, kallikrein, and vWF are also found to be increased in T2DM [25].

However, the above-mentioned biomarkers are often used at later stages of T2DM when atherothrombotic changes and CV complications have already occurred. Researchers are now seeking a diagnostic tool that could be utilized to predict the risk of CVD in the DM population as early in the disease as possible. This could not only help slow the process of atherosclerosis and CVD development, but also aid the clinician in adjusting the optimal pharmacological treatment tailored to the needs of individual patients, without exposing them to the unnecessarily high risk of adverse effects.

Since miRNAs can be easily measured by real-time polymerase chain reactions (rt-PCR) in both plasma or serum, they have attracted special interest as potential novel biomarkers and an instrument to discover the background of platelet gene expression [52]. Platelets and platelet microvesicles (PMVs) harbour large amounts of miRNAs, which contribute substantially to the pool of 
circulating miRNAs. The most highly expressed miRNAs in platelets are miR-223, miR-126, miR-197, miR-24, and miR-21 [22]. Furthermore, the described miRNAs have been associated with CVD, indicating their potential use for risk the assessment in CVD and the monitoring of antiplatelet drug efficacy $[53,54]$.

The role of circulating miRNA in primary prevention of cardiovascular events in T2DM. MiRNAs are highly conserved, noncoding, 20-22 nucelotide long RNAs that modify gene expression at the post-transcriptional level. Platelets harbour a complex miRNA repertoire, hence contribute to the pool of circulating miRNA and can be studied and observed for potential clinical application [22].

Originally known as moderate biological modifiers, miRNAs have emerged as powerful regulators of gene expression in platelets, which suggests they might play a role in dynamic disease progression and the development of CV complications. Mounting evidence about the impact of miRNAs on the pathogenesis of CVD indicates potential diagnostic and therapeutic use of these molecules. Due to the relatively easy acquisition of plasma miRNA, biochemical stability, high diagnostic sensitivity, correlation with the severity of disease processes, as well as dependence on the applied therapy, miRNAs can become valuable biomarkers in the evaluation of platelet activation and inflammation, and response to used treatment, such as ASA. miRNAs provide opportunities to monitor platelet function and vascular condition in T2DM patients, and therefore can be used clinically as a marker of efficacy of antiplatelet therapy [55].

A few miRNAs have been associated with CV complications and T2DM. An extensive description based on a literature review has been published by the authors of the presented study; however, this manuscript outlines the most important miRNAs known to have variable expression in T2DM [56]. The expression of miR-223, as well as miR-140, miR-126 and miR-26b, is reduced in platelets of DMs causing upregulation of P2Y12 receptor and P-selectin, and hence contributing to platelet hyperactivation [57]. On the other hand, Duan et al. showed that downregulation of miR-223 and miR-146a linked to hyperglycaemia, mediates platelet activation in T2DM [58]. Moreover, circulating levels of miR-223 were found to independently predict the response to clopidogrel treatment, which demonstrates the potential use of this miR-223 in the assessment of efficacy of antiplatelet therapy [59]. Also, miR-126 has been linked to T2DM. Zampetaki et al. observed reduced levels of miR-126 in normal glucose, impaired fasting glucose/impaired glucose tolerance and T2DM [60]. In another study, Zampetaki et al. reported that evaluated miRNAs, including miR-197, were mainly expressed in platelets and indicated that the loss of miR197 might suggest abnormal platelet function in the T2DM population [61]. Decreased plasma levels of miR-197 were also demonstrated in patients with manifest T2DM [62].

Another miRNA of interest is miR-191, which was found to be expressed at a 3- to 6-fold reduced plasma levels in T2DM versus healthy study participants. Despite limited usefulness of the role of miR-191, the available results show likely involvement of this miRNA in T2DM patients [63]. Furthermore, the plasma level of miR-21 was reported to be decreased in T2DM $[62,64]$. Olivieri et al. showed similar trends; however, they found that the expression of miR-21-5p was higher in patients with T2DM and major cardiovascular events, compared to other T2DM patients [65]. The evidence demonstrates that the described miRNAs have different expression between T2DM- and non-T2DM groups, as well was during cardiovascular events, and thus might assist in the selection, choosing and monitoring of the primary prevention strategy in T2DM patients.

Furthermore, circulating miRNAs were described as potential biomarkers of CVD in general $[55,66,67,68]$. Since the discovery of circulating miRNAs in 2008, they have been studied in the context of acute MI, CHD, hypertension and heart failure, among others. As a result, research has shown that specific miRNAs are more sensitive and specific than currently used biomarkers [67-68]. In particular, CHD has been the focus of attention for research groups elucidating the influence of miRNA on various CV disorders. So far, several studies have been conducted to evaluate the relationship between miRNAs and CHD, and the promising findings provide foundation on which subsequent trials can be designed and performed $[69,70,71]$. Interestingly, Buraczynska et al. found that microRNA-196a2 polymorphism contributes to the risk of CVD in T2DM, suggesting that further research on miRNA might provide answers on how to utilize these molecules for CV risk stratification, specifically in the DM population [72].

Even though the clinical use of miRNA in CVD risk stratification models is not recommended at present, the combination of circulating miRNAs with conventional biological markers could substantially improve the diagnostic methods of detection of CVD in the future.

\section{CONCLUSIONS}

The currently available pharmacological treatment modalities used for the purpose of primary prevention, act by hindering clot formation, hence protecting the patient from thrombo-ischemic events, while simultaneously increasing the risk of GI bleeding and haemorrhagic stroke. Despite the absence of global consensus or recommendations on optimal, safe and individual-focused antiplatelet therapy for primary prevention in T2DM, the most commonly used drug nowadays is ASA. However, among patients without CVD and low 10-year CVD risk, the risks of adverse effects linked to ASA outweigh the athero-protective benefit. Hira et al. conducted a study to evaluate the frequency and practice-level variation in inappropriate ASA use for primary prevention. The results showed that $11.6 \%$ pf patients in the studied national registry were given inappropriate ASA therapy for primary prevention, indicating that its administration could be further improved [73].

It is worth mentioning that ASA-based treatment strategies cause controversies not only due to the increased risk of side effects, but also due to the suboptimal effectiveness of the drug in a considerable group of patients. Since the mechanisms underlying variable response to ASA in diabetics have not been explicitly elucidated, it may lead us to think that other factors may be held responsible.

The biologically diverse characteristics of miRNA make them a promising novel biomarker and a potential tool for better risk stratification, as well as antiplatelet therapy assessment and optimization. The association between miRNAs and CV risk factor pathology, which often leads to subsequent $\mathrm{CVD}$, justify the need for further and more 
extensive studies of their function in order develop miRNA diagnostic, and perhaps therapeutic, platform to be used in the primary prevention of CVD in T2DM.

\section{Conflicts of interest}

The authors have no conflicts of interest.

\section{REFERENCES}

1. Fox CS, Golden SH, Anderson C, Bray GA, Burke LE, de Boer IH, Deedwania P, Eckel RH, Ershow AG, Fradkin J, Inzucchi SE, Kosiborod M, Nelson RG, Patel MJ, Pignone M, Quinn L, Schauer PR, Selvin E, Vafiadis DK; American Heart Association Diabetes Committee of the Council on Lifestyle and Cardiometabolic Health; Council on Clinical Cardiology, Council on Cardiovascular and Stroke Nursing, Council on Cardiovascular Surgery and Anesthesia, Council on Quality of Care and Outcomes Research; American Diabetes Association. Update on Prevention of Cardiovascular Disease in Adults With Type 2 Diabetes Mellitus in Light of Recent Evidence: A Scientific Statement From the American Heart Association and the American Diabetes Association. Diabetes Care. 2015 Sep; 38(9): 1777-803. doi: 10.2337/ dci15-0012.

2. Kubisz P, Stanicakovs L, Stasko J, Galajda P, Mokan M. Endothelial and platelet markers in diabetes mellitus type 2. World J Diabetes. $2015 \mathrm{Apr}$ 15; 6(3): 423-31. doi: 10.4239/wjd.v6.i3.423.

3. Paneni F, Beckman JA, Creager MA, Cosentino F. Diabetes and vascular disease: pathophysiology, clinical consequences, and medical therapy: part I. Eur Heart J. 2013 Aug; 34(31): 2436-43. doi: 10.1093/eurheartj/ eht149.

4. Haffner SM, Lehto S, Rönnemaa T, Pyörälä K, Laakso M. Mortality from coronary heart disease in subjects with type 2 diabetes and in nondiabetic subjects with and without prior myocardial infarction. $\mathrm{N}$ Engl J Med. 1998 Jul 23; 339(4): 229-34.

5. Pomero F, Di Minno MN, Fenoglio L, Gianni M, Ageno W, Dentali F. Is diabetes a hypercoagulable state? A critical appraisal. Acta Diabetol. 2015 Dec; 52(6): 1007-16. doi: 10.1007/s00592-015-0746-8.

6. Morel O, Jesel L, Abbas M, Morel N. Prothrombotic changes in diabetes mellitus. Semin Thromb Hemost. 2013 Jul; 39(5): 477-88. doi: 10.1055/s0033-1343888.

7. Association AD. Standards of Medical Care in Diabetes-2016. Diabetes Care 2016; 39: 60-71.

8. Cardiovascular Disease and Risk Management. Diabetes Care. 2016; 39: 60-71.

9. Pignone M, Alberts MJ, Colwell JA, Cushman M, Inzucchi SE, Mukherjee D, Rosenson RS, Williams CD, Wilson PW, Kirkman MS. Aspirin for primary prevention of cardiovascular events in people with diabetes: a position statement of the American Diabetes Association, a scientific statement of the American Heart Association, and an expert consensus document of the American College of Cardiology Foundation. Circulation. 2010 Jun 22; 121(24): 2694-701. doi: 10.1161/ CIR.0b013e3181e3b133.

10. Piepoli MF, Hoes AW, Agewall S, Albus C, Brotons C, Catapano AL, Cooney MT, Corrà U, Cosyns B, Deaton C, Graham I, Hall MS, Hobbs FDR, Løchen ML, Löllgen H, Marques-Vidal P, Perk J, Prescott E, Redon J, Richter DJ, Sattar N, Smulders Y, Tiberi M, van der Worp HB, van Dis I, Verschuren WMM, Binno S; ESC Scientific Document Group. 2016 European Guidelines on cardiovascular disease prevention in clinical practice: The Sixth Joint Task Force of the European Society of Cardiology and Other Societies on Cardiovascular Disease Prevention in Clinical Practice (constituted by representatives of 10 societies and by invited experts)Developed with the special contribution of the European Association for Cardiovascular Prevention \& Rehabilitation (EACPR). Eur Heart J. 2016 Aug 1; 37(29): 2315-2381. doi: 10.1093/ eurheartj/ehw106.

11. Halvorsen S, Andreotti F, ten Berg JM, Cattaneo M, Coccheri S, Marchioli R, Morais J, Verheugt FW, De Caterina R. Aspirin therapy in primary cardiovascular disease prevention: a position paper of the European Society of Cardiology working group on thrombosis. J Am Coll Cardiol. 2014 Jul 22; 64(3): 319-27. doi: 10.1016/j.jacc.2014.03.049.

12. Rollini F, Franchi F, Muñiz-Lozano A, Angiolillo DJ. Platelet function profiles in patients with diabetes mellitus. J Cardiovasc Transl Res. 2013 Jun; 6(3): 329-45. doi: 10.1007/s12265-013-9449-0.

13. Kumbhani DJ, Marso SP, Alvarez CA, McGuire DK. State-of-the-Art: Hypo-responsiveness to oral antiplatelet therapy in patients with type
2 diabetes mellitus. Curr Cardiovasc Risk Rep. 2015 Jan; 9: 4. doi: 10.1007/s12170-014-0430-5

14. Yazbek N, Bapat A, Kleiman N. Platelet abnormalities in diabetes mellitus. Coron Artery Dis. 2003; 14: 365-71. doi: 10.1097/01. mca.0000085138.16622.9e.

15. Postula M, Kaplon-Cieslicka A, Rosiak M, Kondracka A, Serafin A, Filipiak KJ, Czlonkowski A, Opolski G, Janicki PK. Genetic determinants of platelet reactivity during acetylsalicylic acid therapy in diabetic patients: evaluation of 27 polymorphisms within candidate genes. J Thromb Haemost. 2011; 9(11): 2291-301. doi: 10.1111/j.15387836.2011.04482.x.

16. Natarajan A, Zaman AG, Marshall SM. Platelet hyperactivity in type 2 diabetes: role of antiplatelet agents. Diab Vasc Dis Res. 2008; 5: 138-44. doi: 10.3132/dvdr.2008.023.

17. Ferroni P, Basili S, Falco A, Davi G. Platelet activation in type 2 diabetes mellitus. J Thromb Haemost. 2004; 2: 1282-91. doi: 10.1111/j.15387836.2004.00836.x

18. McRedmond JP, Park SD, Reilly DF, Coppinger JA, Maguire PB, Shields DC, Fitzgerald DJ. Integration of proteomics and genomics in platelets: a profile of platelet proteins and platelet-specific genes. Mol Cell Proteomics. 2004 Feb; 3(2): 133-44. doi: 10.1074/mcp.M300063MCP200.

19. Dangwal S, Thum T. MicroRNAs in platelet biogenesis and function. Thromb Haemost. 2012 Oct; 108(4): 599-604. doi: 10.1160/TH12-030211.

20. Wang K, Yuan Y, Cho JH, McClarty S, Baxter D, Galas DJ. Comparing the MicroRNA spectrum between serum and plasma. PLoS One. 2012; 7(7): e41561. doi: 10.1371/journal.pone.0041561.

21. Shi R, Ge L, Zhou X, Ji WJ, Lu RY, Zhang YY, Zeng S, Liu X, Zhao JH, Zhang WC, Jiang TM, Li YM. Decreased platelet miR-223 expression is associated with high on-clopidogrel platelet reactivity. Thromb Res. 2013 Jun; 131(6): 508-13. doi: 10.1016/j.thromres.2013.02.015.

22. Choi JL, Li S, Han JY. Platelet function tests: a review of progresses in clinical application. Biomed Res Int. 2014; 2014: 456569. doi: $10.1155 / 2014 / 456569$

23. Iaconetti C, Sorrentino S, De Rosa S, Indolfi C. Exosomal miRNAs in Heart Disease. Physiology (Bethesda). 2016 Jan; 31(1): 16-24. doi: 10.1152/physiol.00029.2015.

24. Santilli F, Pignatelli P, Violi F, Davì G. Aspirin for primary prevention in diabetes mellitus: from the calculation of cardiovascular risk and risk/benefit profile to personalised treatment. Thromb Haemost. 2015 Nov; 114(5): 876-82. doi: 10.1160/TH15-03-0202.

25. Carr ME. Diabetes mellitus: a hypercoagulable state. J Diabetes Complications. 2001 Jan-Feb; 15(1): 44-54.

26. Third Report of the National Cholesterol Education Program (NCEP) Expert Panel on Detection, Evaluation, and Treatment of High Blood Cholesterol in Adults (Adult Treatment Panel III) final report. Circulation 2002; 106: 3143-3421.

27. Angiolillo DJ, Bernardo E, Sabaté M, Jimenez-Quevedo P, Costa MA, Palazuelos J, Hernández-Antolin R, Moreno R, Escaned J, Alfonso F, Bañuelos C, Guzman LA, Bass TA, Macaya C, Fernandez-Ortiz A. Impact of platelet reactivity on cardiovascular outcomes in patients with type 2 diabetes mellitus and coronary artery disease. J Am Coll Cardiol. 2007 Oct 16; 50(16): 1541-7. doi: 10.1016/j.jacc.2007.05.049.

28. Jung JH, Tantry US, Gurbel PA, Jeong YH. Current antiplatelet treatment strategy in patients with diabetes mellitus. Diabetes Metab J. 2015 Apr; 39(2): 95-113. doi: 10.4093/dmj.2015.39.2.95.

29. Vane JR. Inhibition of prostaglandin synthesis as a mechanism of action for aspirin-like drugs. Nat New Biol. 1971 Jun 23; 2 31(25): 232-5.

30. Nguyen KX, Marinac JS, Sun C. Aspirin for primary prevention in patients with diabetes mellitus. Fam Med. 2005 Feb; 37(2): 112-7.

31. Casado-Arroyo R, Sostres C, Lanas A. Optimizing the use of aspirin for cardiovascular prevention. Drugs. 2013 Jun; 73(8): 803-14. doi: 10.1007/s40265-013-0061-z.

32. Vandvik PO, Lincoff AM, Gore JM, Gutterman DD, Sonnenberg FA, Alonso-Coello P, Akl EA, Lansberg MG, Guyatt GH, Spencer FA. Primary and secondary prevention of cardiovascular disease: Antithrombotic Therapy and Prevention of Thrombosis, 9th ed: American College of Chest Physicians Evidence-Based Clinical Practice Guidelines. Chest. 2012 Feb; 141(2 Suppl): e637S-e668S. doi: 10.1378/ chest.11-2306.

33. Davì G, Catalano I, Averna M, Notarbartolo A, Strano A, Ciabattoni G, Patrono C. Thromboxane biosynthesis and platelet function in type II diabetes mellitus. N Engl J Med. 1990 Jun 21; 322(25): 1769-74. doi: 10.1056/NEJM199006213222503.

34. Zhang C, Sun A, Zhang P, Wu C, Zhang S, Fu M, Wang K, Zou Y, Ge J. Aspirin for primary prevention of cardiovascular events in patients 
with diabetes: A meta-analysis. Diabetes Res Clin Pract. 2010 Feb; 87(2): 211-8. doi: 10.1016/j.diabres.2009.09.029.

35. Bartolucci AA, Tendera M, Howard G. Meta-analysis of multiple primary prevention trials of cardiovascular events using aspirin. Am J Cardiol. 2011 Jun 15; 107(12): 1796-801. doi: 10.1016/j.amjcard.2011.02.325.

36. Bartolucci AA, Howard G. Meta-analysis of data from the six primary prevention trials of cardiovascular events using aspirin. Am J Cardiol. 2006 Sep 15; 98(6): 746-50. Epub 2006 Jul 26.

37. Butalia S, Leung AA, Ghali WA, Rabi DM. Aspirin effect on the incidence of major adverse cardiovascular events in patients with diabetes mellitus: a systematic review and meta-analysis. Cardiovasc Diabetol. 2011 Apr 1; 10: 25. doi: 10.1186/1475-2840-10-25.

38. Stavrakis S, Stoner JA, Azar M, Wayangankar S, Thadani U. Low-dose aspirin for primary prevention of cardiovascular events in patients with diabetes: a meta-analysis. Am J Med Sci. 2011 Jan; 341(1): 1-9. doi: 10.1097/MAJ.0b013e3181f1fba8.

39. Sutcliffe P, Connock M, Gurung T, Freeman K, Johnson S, Kandala NB, Grove A, Gurung B, Morrow S, Clarke A. Aspirin for prophylactic use in the primary prevention of cardiovascular disease and cancer: a systematic review and overview of reviews. Health Technol Assess. 2013 Sep; 17(43): 1-253. doi: 10.3310/hta17430.

40. Xie M, Shan Z, Zhang Y, Chen S, Yang W, Bao W, Rong Y, Yu X, Hu FB, Liu L. Aspirin for primary prevention of cardiovascular events: meta-analysis of randomized controlled trials and subgroup analysis by sex and diabetes status. PLoS One. 2014 Oct 31; 9(10): e90286. doi: 10.1371/journal.pone.0090286.

41. Webster R, Patel A, Selak V, Billot L, Bots ML, Brown A, Bullen C, Cass A, Crengle S, Raina Elley C, Grobbee DE, Neal B, Peiris D, Poulter N, Prabhakaran D, Rafter N, Stanton A, Stepien S, Thom S, Usherwood T, Wadham A, Rodgers A; SPACE Collaboration. Effectiveness of fixed dose combination medication ('polypills') compared with usual care in patients with cardiovascular disease or at high risk: A prospective, individual patient data meta-analysis of 3140 patients in six countries. Int J Cardiol. 2016 Feb 15; 205: 147-156. doi: 10.1016/j.ijcard.2015.12.015.

42. Kokoska LA, Wilhelm SM, Garwood CL, Berlie HD. Aspirin for primary prevention of cardiovascular disease in patients with diabetes: A meta-analysis. Diabetes Res Clin Pract. 2016 Oct; 120: 31-9. doi: 10.1016/j.diabres.2016.07.012.

43. De Berardis G, Sacco M, Evangelista V, Filippi A, Giorda CB, Tognoni G, Valentini U, Nicolucci A; ACCEPT-D Study Group. Aspirin and Simvastatin Combination for Cardiovascular Events Prevention Trial in Diabetes (ACCEPT-D): design of a randomized study of the efficacy of low-dose aspirin in the prevention of cardiovascular events in subjects with diabetes mellitus treated with statins. Trials. 2007 Aug 28;8:21.

44. Aung T, Haynes R, Barton J, Cox J, Murawska A, Murphy K, Lay M, Armitage J, Bowman L; ASCEND Study Collaborative Group. Cost-effective recruitment methods for a large randomised trial in people with diabetes: A Study of Cardiovascular Events iN Diabetes (ASCEND). Trials. 2016 Jun 13; 17(1): 286. doi: 10.1186/s13063-0161354-9.

45. Derosa G, Mugellini A, Pesce RM, D’Angelo A, Maffioli P. A study about the relevance of adding acetylsalicylic acid in primary prevention in subjects with type 2 diabetes mellitus: effects on some new emerging biomarkers of cardiovascular risk. Cardiovasc Diabetol. 2015 Jul 30; 14: 95. doi: 10.1186/s12933-015-0254-8.

46. Kapłon-Cieślicka A, Rosiak M, Postuła M, Serafin A, Kondracka A, Opolski G, Filipiak KJ. Predictors of high platelet reactivity during aspirin treatment in patients with type 2 diabetes. Kardiol Pol. 2013; 71(9): 893-902. doi: 10.5603/KP.2013.0055.

47. Li L, Qu C, Wu X, Dai J, Lu Y, Gong Y, You R, Liu Y. Patterns and levels of platelet glycosylation in patients with coronary heart disease and type 2 diabetes mellitus. J Thromb Thrombolysis. 2018 Jan; 45(1): 56-65. doi: 10.1007/s11239-017-1573-2.

48. Israels SJ, McNicol A, Dean HJ, Cognasse F, Sellers EA. Markers of platelet activation are increased in adolescents with type 2 diabetes. Diabetes Care. 2014 Aug; 37(8): 2400-3. doi: 10.2337/dc13-2718.

49. El-Mesallamy H, Hamdy N, Suwailem S, Mostafa S. Oxidative stress and platelet activation: markers of myocardial infarction in type 2 diabetes mellitus. Angiology. 2010 Feb-Mar; 61(1): 14-8. doi: $10.1177 / 0003319709340891$.

50. Zhang X, McGeoch SC, Johnstone AM, Holtrop G, Sneddon AA, MacRury SM, Megson IL, Pearson DW, Abraham P, De Roos B, Lobley GE, O'Kennedy N. Platelet-derived microparticle count and surface molecule expression differ between subjects with and without type 2 diabetes, independently of obesity status. J Thromb Thrombolysis. 2014 May; 37(4): 455-63. doi: 10.1007/s11239-013-1000-2.
51. Liani R, Halvorsen B, Sestili S, Handberg A, Santilli F, Vazzana N, Formoso G, Aukrust P, Davì G. Plasma levels of soluble CD36, platelet activation, inflammation, and oxidative stress are increased in type 2 diabetic patients. Free Radic Biol Med. 2012 Apr 15; 52(8): 1318-24. doi: 10.1016/j.freeradbiomed.2012.02.012.

52. Kaudewitz D, Skroblin P, Bender LH, Barwari T, Willeit P, Pechlaner R, Sunderland NP, Willeit K, Morton AC, Armstrong PC, Chan MV, Lu R, Yin X, Gracio F, Dudek K, Langley SR, Zampetaki A, de Rinaldis E, Ye S, Warner TD, Saxena A, Kiechl S, Storey RF, Mayr M. Association of MicroRNAs and YRNAs With Platelet Function. Circ Res. 2016 Feb 5; 118(3): 420-432. doi: 10.1161/CIRCRESAHA.114.305663.

53. Nishiguchi T, Imanishi T, Akasaka T. MicroRNAs and cardiovascular diseases. Biomed Res Int. 2015: 682857. doi:10.1155/2015/682857

54. Kondkar AA, Abu-Amero KK. Utility of circulating microRNAs as clinical biomarkers for cardiovascular diseases. Biomed Res Int. 2015: 8 21823. doi:10.1155/2015/821823

55. De Rosa S, Curcio A, Indolfi C. Emerging role of microRNAs in cardiovascular diseases. Circ J. 2014; 78(3): 567-75. Epub 2014 Feb 13.

56. Pordzik J, Pisarz K, De Rosa S, Jones AD, Eyileten C, Indolfi C, Malek L, Postula M. The Potential Role of Platelet-Related microRNAs in the Development of Cardiovascular Events in High-Risk Populations, Including Diabetic Patients: A Review. Front Endocrinol (Lausanne). 2018 Mar 20; 9: 74. doi: 10.3389/fendo.2018.00074.

57. Feje, Z, Póliska S, Czimmerer Z, Káplár M, Penyige A, Gál Szabó G, et al. Hyperglycemia suppresses microRNA expression in platelets to increase P2RY12 and SELP levels in type 2 diabetes mellitus. Thromb. Haemost. 2017; 117: 529-542. doi: 10.1160/TH16-04-0322.

58. Duan X, Zhan Q, Song B, Zeng S, Zhou J, Long Y, et al. Detection of platelet microRNA expression in patients with diabetes mellitus with or without ischemic stroke. J Diabetes Complications. 2017; 28: 705-710. doi: 10.1016/j.jdiacomp.2014.04.012.

59. Zhang YY, Zhou X, Ji WJ, Shi R, Lu RY, Li JL, et al. Decreased circulating microRNA-223 level predicts high on-treatment platelet reactivity in patients with troponin-negative non-ST elevation acute coronary syndrome. J. Thromb. Thrombolysis. 2014; 38: 65-72. doi: 10.1007/ s11239-013-1022-9.

60. Zampetaki A, Willeit P, Drozdov I, Kiechl S, Mayr M. Profiling of circulating microRNAs: from single biomarkers to re-wired networks. Cardiovasc Res. 2012; 93: 555-562. doi: 10.1093/cvr/cvr266.

61. Zampetaki A, Willeit P, Tilling L, Drozdov I, Prokopi M, Renard JM, et al. Prospective study on circulating microRNAs and risk of myocardial infarction. J Am Coll Cardiol. 2012; 60: 290-299. doi: 10.1016/j.jacc.2012.03.056.

62. Zampetaki A, Kiechl S, Drozdov I, Willeit P, Mayr U, Prokopi M, et al. Plasma microRNA profiling reveals loss of endothelial miR-126 and other microRNAs in type 2 diabetes. Circ Res. 2010; 107: 810-817. doi: 10.1161/CIRCRESAHA.110.226357.

63. Dangwal S, Stratmann B, Bang C, Lorenzen JM. Kumarswamy R, Fiedler J, et al. Impairment of Wound Healing in Patients With Type 2 Diabetes Mellitus Influences Circulating MicroRNA Patterns via Inflammatory Cytokines. Arterioscler Thromb Vasc Biol. 2015; 35: 1480-1488. doi: 10.1161/ATVBAHA.114.305048.

64. Fuentes E, Palomo I, Alarcón M. Platelet miRNAs and cardiovascular diseases. Life Sci. 2015; 133: 29-44. doi: 10.1016/j.lfs.2015.04.016.

65. Olivieri F, Spazzafumo L, Bonafè M, Recchioni R, Prattichizzo F, Marcheselli F, et al. MiR-21-5p and miR-126a-3p levels in plasma and circulating angiogenic cells: relationship with type 2 diabetes complications. Oncotarget. 2015; 6: 35372-82. doi: 10.18632/ oncotarget.6164.

66. De Rosa S, Indolfi C. Circulating microRNAs as Biomarkers in Cardiovascular Diseases. EXS. 2015; 106: 139-149. doi: 1007/978-30348-0955-9 6.

67. Wang F, Chen C, Wang D. Circulating microRNAs in cardiovascular diseases: from biomarkers to therapeutic targets. Front Med. $2014 \mathrm{Dec}$; 8(4): 404-18. doi: 10.1007/s11684-014-0379-2.

68. Fichtlscherer S, De Rosa S, Fox H, Schwietz T, Fischer A, Liebetrau C, Weber M, Hamm CW, Röxe T, Müller-Ardogan M, Bonauer A, Zeiher AM, Dimmeler S. Circulating microRNAs in patients with coronary artery disease. Circ Res. 2010 Sep 3; 107(5): 677-84. doi: 10.1161/CIRCRESAHA.109.215566.

69. Schulte C, Molz S, Appelbaum S, Karakas M, Ojeda F, Lau DM, Hartmann T, Lackner KJ, Westermann D, Schnabel RB, Blankenberg S, Zeller T. miRNA-197 and miRNA-223 Predict Cardiovascular Death in a Cohort of Patients with Symptomatic Coronary Artery Disease. PLoS One. 2015 Dec 31; 10(12): e0145930. Doi: 10.1371/journal.pone.0145930.

70. Jansen F, Yang X, Proebsting S, Hoelscher M, Przybilla D, Baumann K, Schmitz T, Dolf A, Endl E, Franklin BS, Sinning JM, Vasa-Nicotera 
M, Nickenig G, Werner N. MicroRNA expression in circulating microvesicles predicts cardiovascular events in patients with coronary artery disease. J Am Heart Assoc. 2014 Oct 27; 3(6): e001249. doi: 10.1161/JAHA.114.001249.

71. Wang L, Zhi H, Li Y, Ma G, Ye X, Yu X, Yang T, Jin H, Lu Z, Wei P. Polymorphism in miRNA-1 target site and circulating miRNA-1 phenotype are associated with the decreased risk and prognosis of coronary artery disease. Int J Clin Exp Pathol. 2014 Jul 15; 7(8): $5093-$ 102.

72. Buraczynska M, Zukowski P, Wacinski P, Ksiazek K, Zaluska W. Polymorphism in microRNA-196a2 contributes to the risk of cardiovascular disease in type 2 diabetes patients. J Diabetes Complications. 2014 Sep-Oct; 28(5): 617-20. doi: 10.1016/j. jdiacomp.2014.05.006.

73. Hira RS, Kennedy K, Nambi V, Jneid H, Alam M, Basra SS, Ho PM, Deswal A, Ballantyne CM, Petersen LA, Virani SS. Frequency and practice-level variation in inappropriate aspirin use for the primary prevention of cardiovascular disease: insights from the National Cardiovascular Disease Registry's Practice Innovation and Clinical Excellence registry. J Am Coll Cardiol. 2015 Jan 20; 65(2): 111-21. doi: 10.1016/j.jacc.2014.10.035.

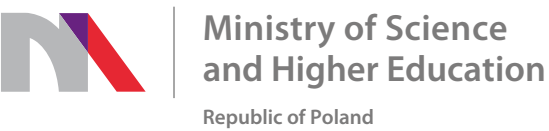

Generation of the DOI (Digital Object Identifier) - task financed under the agreement No. 618/P-DUN/2019 by the Minister of Science and Higher Education 